\section{In Vitro Inhibitory Effects of Cannabinoids on Progesterone 17 $\alpha$ - Hydroxylase Activity in Rat Testis Microsomes}

\author{
Tatsuya Funahashi, ${ }^{a}$ Hideharu Ikeuchi, ${ }^{a}$ \\ Satoshi Yamaori, ${ }^{a}$ Toshiyuki Kimura, ${ }^{a}$ \\ Ikuo Yamamoto, ${ }^{b}$ and Kazuhito Watanabe ${ }^{*, a}$ \\ ${ }^{a}$ Department of Hygienic Chemistry, Faculty of Pharmaceuti- \\ cal Sciences, Hokuriku University, Ho-3 Kanagawa-machi, \\ Kanazawa 920-1181, Japan and ${ }^{b}$ Department of Hygienic \\ Chemistry, School of Pharmaceutical Sciences, Kyushu Univer- \\ sity of Health and Welfare, 1714-1 Yoshino-machi, Nobeoka, \\ Miyazaki 882-8508, Japan \\ (Received January 17, 2005; Accepted February 26, 2005)
}

The inhibitory effects of three major cannabinoids [ $\Delta^{9}$-tetrahydrocannabinol (THC), cannabidiol (CBD), cannabinol (CBN)] contained in marijuana, an abused drug, on progesterone $17 \alpha$-hydroxylase activity in rat testis microsomes were investigated. Microsomal progesterone $17 \alpha$-hydroxylase activity was significantly inhibited in the presence of more than $50 \mu \mathrm{M}$ of $\Delta^{9}$ THC and CBN compared with control activity, and the $\mathrm{IC}_{50}$ values for $\boldsymbol{\Delta}^{\mathbf{9}}$-THC and $\mathrm{CBN}$ were estimated to be 42.8 and $32.9 \mu \mathrm{M}$, respectively. CBD showed less but significant inhibitory effects on $17 \alpha$-hydroxylase activity at concentrations greater than $100 \mu \mathrm{M}$, and the $\mathrm{IC}_{50}$ value for the cannabinoid was estimated to be $290.9 \mu \mathrm{M}$. Kinetic analysis using double reciprocal plots showed that the type of inhibition by CBN was competitive, whereas that of $\Delta^{9}$-THC and CBD was the mixed type. These results suggest that the inhibition may be due to metabolic interactions between each cannabinoid and $17 \alpha$-hydroxylase.

Key words — cannabinoid, $17 \alpha$-hydroxylase, testis, enzyme inhibition

\section{INTRODUCTION}

$\Delta^{9}$-Tetrahydrocannabinol (THC), cannabidiol (CBD), and cannabinol (CBN), the three major can-

*To whom correspondence should be addressed: Department of Hygienic Chemistry, Faculty of Pharmaceutical Sciences, Hokuriku University, Ho-3 Kanagawa-machi, Kanazawa 9201181, Japan. Tel.: +81-76-229-6220; Fax: +81-76-229-6221; Email: k-watanabe@hokuriku-u.ac.jp nabinoids isolated from Cannabis Sativa L. (Fig. 1), have been reported to exert many effects on sex hormone production and reproductive functions in mammals. ${ }^{1-4)}$ Several investigators have examined the effects of cannabinoids on the enzymes involved in steroid biosynthesis. An early in vitro study indicated that no change occurred in the transformation of either pregnenolone or progesterone to testosterone with $\Delta^{9}$-THC $1.0 \mu \mathrm{g} / \mathrm{ml}$, a dose at which both $\Delta^{9}$-THC and $\mathrm{CBN}$ caused a greater than $60 \%$ decrease in testosterone biosynthesis in mouse Leydig cells. ${ }^{5)}$ Later, it was found that $\Delta^{9}$-THC inhibited the activity of the cholesterol esterase involved in the conversion of cholesterol to pregnenolone in crude Leydig cell preparations ${ }^{6}$ and also in the supernatants from rat adrenal homogenate. ${ }^{7}$ Moreover, in vitro experiments indicated that THC can exert a variety of direct effects on the testis including inhibition of testosterone production, and that $\mathrm{CBD}$ and $\mathrm{CBN}$, both of which are devoid of psychoactivity, are also capable of directly influencing testicular function. ${ }^{8-10)}$ Recently, we have reported that the conversion of progesterone to $17 \alpha$-hydroxyprogesterone in rat testis microsomes was significantly inhibited by CBD, $\mathrm{CBN}$, and $\Delta^{9}$-THC. ${ }^{11)} \mathrm{A}$ single microsomal enzyme, $17 \alpha$-hydroxylase (EC 1.14.99.4)/C17,20-lyase (EC 4.1.2.30) (P450 17, CYP17) catalyzes the $17 \alpha$-hydroxylation of pregnenolone and progesterone, and the subsequent cleavage of the C20,21-acetyl group to the corresponding androgens. ${ }^{12)}$ In the adult rat, this enzyme is located in both testicular and duodenal tissues, ${ }^{13)}$ but the adrenal gland contains negligible levels of the enzyme, differing from other mammals including humans. ${ }^{14)}$ The early study suggested that the concentrations of $17 \alpha$-hydroxyprogesterone, androstenedione, and estradiol in mouse testis incubated with human chorionic gonadotropin were not changed by $\Delta^{9}$-THC. ${ }^{15)}$ At present, it is not clear whether cannabinoids function as inhibitors of $17 \alpha$ hydroxylase.

To obtain direct evidence for the inhibitory effects of cannabinoids on $17 \alpha$-hydroxylase activity, we examined the effects of the three major cannabinoids on the kinetic parameters of the enzyme in rat testis microsomes.

\section{MATERIALS AND METHODS}

Chemicals $-\Delta^{9}$-THC, CBD, and CBN were isolated and purified from cannabis leaves using the method reported previously. ${ }^{16)}$ The purities of the 


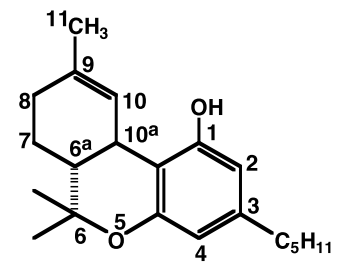

$\Delta^{9}$-Tetrahydrocannabinol

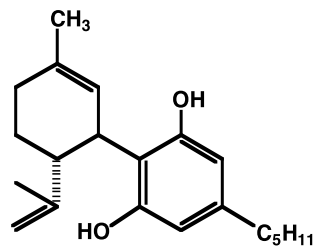

Cannabidiol

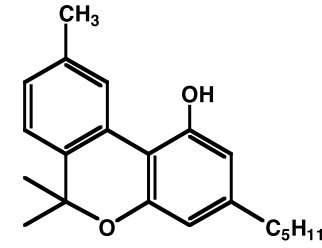

Cannabinol
Fig. 1. Chemical Structures of Major Cannabinoids in Cannabis Sativa L.

cannabinoids were more than $98 \%$ in gas chromatography acccording to the previous methods. ${ }^{11)}$ Progesterone, $17 \alpha$-hydroxyprogesterone, and androstenedione were purchased from Sigma Chemical Co. (St. Louis, MO, U.S.A.). [1,2,6,7- $\left.{ }^{3} \mathrm{H}\right]$ Progesterone $(102.1 \mathrm{Ci} / \mathrm{mmol})$ was obtained from PerkinElmer Life Sciences, Inc. (Boston, MA, U.S.A.). NADP ${ }^{+}$and glucose-6-phosphate were bought from Roche Diagnostics GmbH (Mannheim, Germany). Glucose-6-phosphate dehydrogenase was purchased from Oriental Yeast Co., Ltd. (Tokyo, Japan). All other chemicals and solvents were of the highest grade available from commercial sources.

Animals and Tissue Preparation — Male Sprague-Dawley rats (8 weeks old, Sankyo Lab., Toyama, Japan) were killed by decapitation and their testes were dissected. Testes from three rats were pooled and then homogenized in 3 volumes of $50 \mathrm{mM}$ of potassium phosphate buffer $(\mathrm{pH} 7.4)$ containing sucrose $50 \mathrm{mM}$ and dithiothreitol $0.5 \mathrm{mM}$ with a Potter-Elvehjem-type homogenizer. The homogenate was centrifuged at $9000 \times g$ for $20 \mathrm{~min}$ at $4^{\circ} \mathrm{C}$, and the supernatant was further centrifuged at $105000 \times g$ for $1 \mathrm{hr}$ to yield a microsomal pellet. The pellet was washed twice in the same buffer and suspended in $50 \mathrm{mM}$ of potassium phosphate buffer ( $\mathrm{pH} 7.4$ ) containing sucrose $50 \mathrm{mM}$ and $20 \%$ glycerol.

The protein concentration was determined using the method of Lowry et al. ${ }^{17)}$ with bovine serum albumin as a standard.

\section{Determination of $17 \alpha$-Hydroxylase Activity -}

$17 \alpha$-Hydroxylase activity was determined by mea- suring the oxidation of progesterone to $17 \alpha$ hydroxyprogesterone and androstenedione. In a total volume of $0.5 \mathrm{ml}$ the incubation mixture contained: $100 \mathrm{mM}$ of sodium potassium phosphate buffer ( $\mathrm{pH} 7.4$ ), $0.2 \mu \mathrm{Ci}$ of $\left[1,2,6,7-{ }^{3} \mathrm{H}\right]$ progesterone, an appropriate amount of nonradioactive progesterone dissolved in dimethylsulfoxide (DMSO) : water (1:9), rat testis microsomes, an NADPH-generating system (final concentrations: $\mathrm{NADP}^{+} 0.5 \mathrm{mM}$, glucose 6-phosphate $10 \mathrm{mM}$, glucose-6-phosphate dehydrogenase $1 \mathrm{IU}, \mathrm{MgCl}_{2} 10 \mathrm{mM}$ ). Cannabinoids (dissolved in DMSO) were added to the incubation mixture within the range of $0-300 \mu \mathrm{M}$. DMSO was added to the incubation mixture to give a final concentration of $1 \%$. The reaction mixture was incubated at $37^{\circ} \mathrm{C}$ for $2 \mathrm{~min}$ and transferred to a glass test tube containing $3 \mathrm{ml}$ of diethylether : chloroform (4:1), nonradioactive progesterone, $17 \alpha$-hydroxyprogesterone, and androstenedione (each $10 \mu \mathrm{g}$ ) as the carrier steroids. The mixture was then vortexed vigorously to terminate the reactions and to extract the steroids. After centrifugation at $900 \times g$ for $10 \mathrm{~min}$, the organic phase was transferred to an alternative test tube. After the third extraction, the organic phase was evaporated under $\mathrm{N}_{2}$ gas. The final residue was dissolved in ethanol and subjected to thin-layer chromatography in chloroform : ethyl acetate $(4: 1)$ using Silica gel plates (Whatman K6F Silica gel 60). The region corresponding to $17 \alpha$ hydroxyprogesterone and androstenedione was scraped off under ultraviolet light and transferred to a vial containing scintillation fluid, Clear-sol (Nacalai-Tesque, Kyoto, Japan). The radioactivity was measured in a scintillation spectrometer (Aloka LSC-3500, Tokyo, Japan). After the third extraction, part of the organic phase was subjected to analysis of the radioactivity of extracted tritium. The recovery of tritium radioactivity in this reaction was more than $98 \%$ of that in the substrate. $17 \alpha$-Hydroxylase activity was determined from the sum of $17 \alpha-$ hydroxyprogesterone and androstenedione.

Kinetic Analyses — The kinetic parameters $K_{m}$ and $\mathrm{V}_{\max }$ values were calculated by estimating the corresponding double-reciprocal Lineweaver-Burk plots. The $\mathrm{K}_{\mathrm{i}}$ values were obtained from the slope of each reciprocal plot against the cannabinoid concentration using linear regression analysis. The $\mathrm{IC}_{50}$ values were calculated using nonlinear regression analysis program from the plot of enzyme activity (\%) against the log of cannabinoid concentration (Origin 6.1J, OriginLab. Co., Northampton, MA, U.S.A.). The statistical significance of difference was 


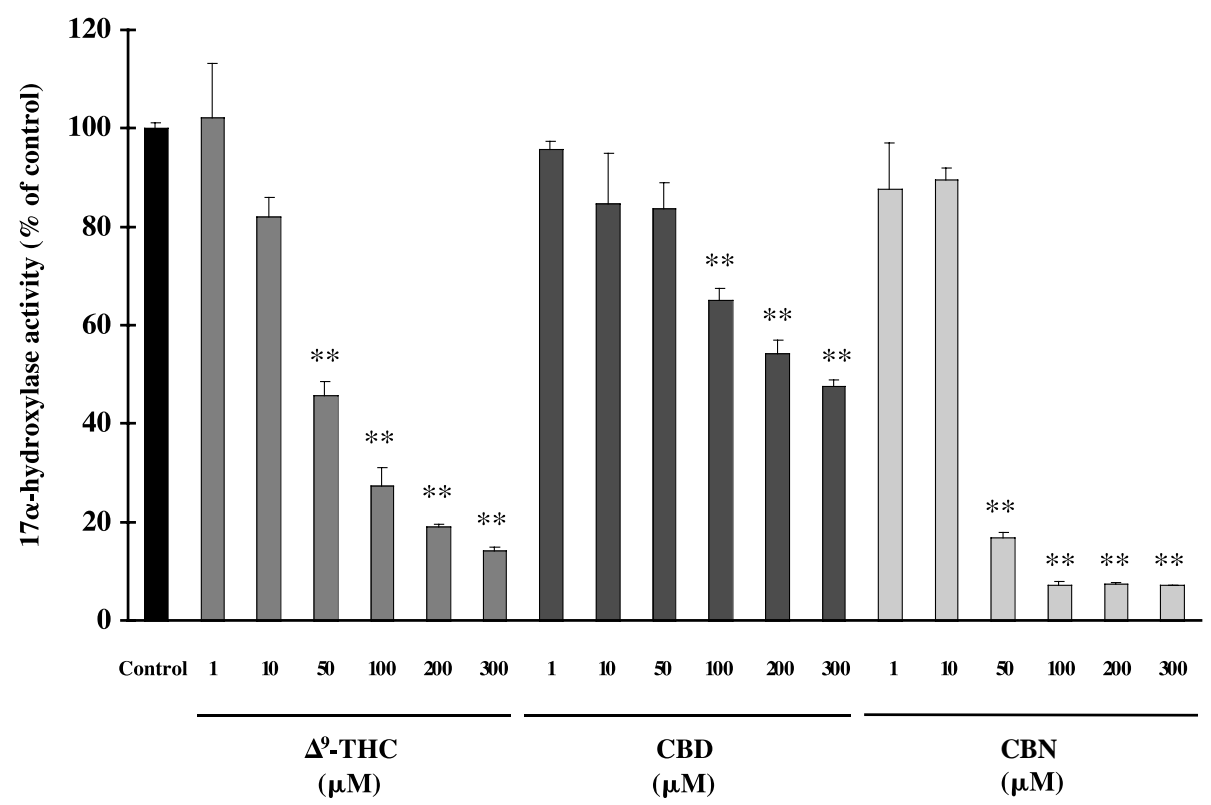

Fig. 2. Effects of Three Major Cannabinoids on Rat Testis $17 \alpha$-Hydroxylase Activity

$17 \alpha$-Hydroxylase activity was expressed as a percentage of the control value \pm S.E.M. obtained from triplicate experiments. The substrate concentration was $75 \mathrm{nM}$. The control activity was $81.9 \pm 1.0 \mathrm{pmol} / \mathrm{min} / \mathrm{mg}$ protein. ${ }^{* *} p<0.01$ as compared with the control group.

calculated using analysis of variance (ANOVA), followed by Bonferroni's multiple comparison tests. Differences were considered statistically significant at the $p<0.01$ level.

\section{RESULTS}

\section{Effects of Cannabinoids on Microsomal $17 \alpha-\mathrm{Hy}$ -} droxylase Activity in Rat Testis

The effects of cannabinoids on rat testis microsomal $17 \alpha$-hydroxylase activity are shown in Fig. 2. $\Delta^{9}$-THC and CBN significantly inhibited $17 \alpha$-hydroxylase activity by 19 and $7 \%$, respectively, as compared with the control at the concentration of $300 \mu \mathrm{M}$. CBN is thought to act as a potent inhibitor at high concentrations. Although $17 \alpha$-hydroxylase activity was also significantly inhibited by CBD at concentrations greater than $100 \mu \mathrm{M}$, the residual activity was reduced to only $48 \%$ compared with the control activity at $300 \mu \mathrm{M}$. CBD also showed comparatively weak but significant inhibition. The $\mathrm{IC}_{50}$ values for $\Delta^{9}$-THC, CBD, and CBN $17 \alpha$-hydroxylase inhibition were 42.8, 290.9, and $32.9 \mu \mathrm{M}$, respectively (Table 1).

\section{Effects of Cannabinoids on Kinetic Parameters} of Rat Testis Microsomal 17 $\alpha$-Hydroxylase

When microsomal $17 \alpha$-hydroxylase activity in rat testis was expressed as the cumulative conversion of $\left[1,2,6,7-{ }^{3} \mathrm{H}\right]$ progesterone $2 \mu \mathrm{M}$ to $17 \alpha$ hydroxyprogesterone and androstenedione, the reaction was found to be linear with the amount of total microsomal protein up to $300 \mu \mathrm{g}$ after 2-min incubation. In the subsequent enzyme assays to measure the kinetic parameters of $17 \alpha$-hydroxylase, the conditions were maintained by incubating $50 \mu \mathrm{g}$ of microsomal protein for $2 \mathrm{~min}$ with up to $0.5 \mu \mathrm{M}$ of progesterone.

The type of testis $17 \alpha$-hydroxylase inhibition by each cannabinoid was examined in kinetic analysis using Lineweaver-Burk plots. Kinetic analyses demonstrated that CBN at the concentration of $100 \mu \mathrm{M}$ caused an increase in the $\mathrm{K}_{\mathrm{m}}$ value (about 30 -fold) without significantly affecting the $\mathrm{V}_{\max }$ value (Table 1). These data suggest that the observed inhibition of $17 \alpha$-hydroxylase activity by CBN is the competitive type. Although $\Delta^{9}$-THC caused an increase in the $\mathrm{K}_{\mathrm{m}}$ value of $17 \alpha$-hydroxylase activity, $\mathrm{V}_{\max }$ was reduced to about $60 \%$ compared with the control activity (Table 1). Moreover, the double reciprocal plot intersected above the 1/[S]-axis (Fig. 3), suggesting that $17 \alpha$-hydroxylase inhibition by $\Delta^{9}$ THC is the mixed type. Similarly, CBD showed a mixed-type inhibition with an increase in the $\mathrm{K}_{\mathrm{m}}$ and a decrease in $\mathrm{V}_{\max }$ values, although the inhibitory effects of the cannabinoid on $17 \alpha$-hydroxylase activity was very weak compared with those of $\Delta^{9}$-THC 
Table 1. Effects of Cannabinoids on Kinetic Parameters of Microsomal $17 \alpha$-Hydroxylase in Rat Testis

\begin{tabular}{lcccc}
\hline \hline & $\mathrm{K}_{\mathrm{m}}(\mathrm{nM})$ & $\mathrm{V}_{\max }(\mathrm{pmol} / \mathrm{min} / \mathrm{mg}$ protein $)$ & $r^{2}$ & $\mathrm{IC}_{50}$ \\
\hline Experiment 1 & & & & \\
$\quad$ Control & 51.3 & 142.9 & 0.9941 & $42.8 \pm 1.1$ \\
$\Delta^{9}$-THC $(50 \mu \mathrm{M})$ & 119.2 & 119.2 & 0.9870 & \\
$\Delta^{9}$-THC $(100 \mu \mathrm{M})$ & 202.2 & 90.9 & 0.9977 & \\
Experiment 2 & & & \\
Control & 41.4 & 133.3 & 0.9757 & \\
CBD $(50 \mu \mathrm{M})$ & 41.7 & 105.3 & 0.9926 & \\
CBD $(100 \mu \mathrm{M})$ & 51.3 & 92.6 & 0.9990 & \\
Experiment 3 & & & & \\
Control & 53.2 & 129.9 & 0.9951 & $32.9 \pm 1.3$ \\
CBN $(50 \mu \mathrm{M})$ & 582.6 & 116.3 & 0.9987 & \\
CBN $(100 \mu \mathrm{M})$ & 1657.6 & 172.4 & 0.9997 & \\
\hline The $\mathrm{K}_{\mathrm{m}}$ and $\mathrm{V}_{\text {mal }}$ values were determined from Lineweaver-Burk plots (Fig. 3). The IC 50 values represent mean \pm S.E.
\end{tabular}

The $\mathrm{K}_{\mathrm{m}}$ and $\mathrm{V}_{\max }$ values were determined from Lineweaver-Burk plots (Fig. 3). The $\mathrm{IC}_{50}$ values represent mean \pm S.E. obtained from non-linear regression analysis mentioned in materials and methods.

A.

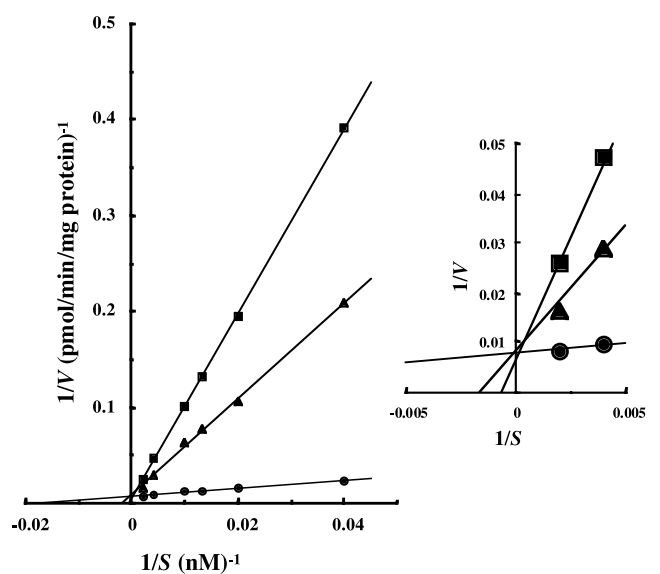

B.

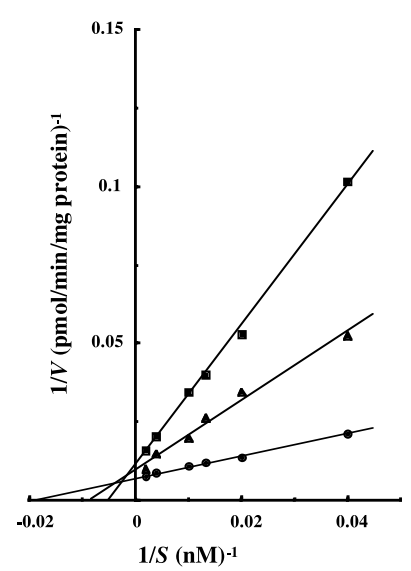

C.

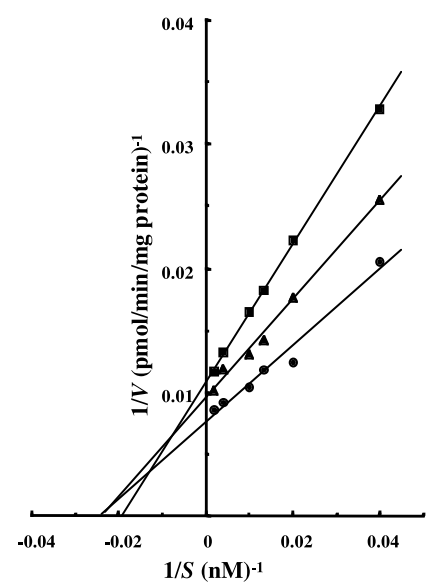

Fig. 3. Inhibition of Rat Testis $17 \alpha$-Hydroxylase Activity by Cannabinoids

$17 \alpha$-Hydroxylase activities are shown by double reciprocal Lineweaver-Burk plots against the concentrations of progesterone in the presence of CBN (A), $\Delta^{9}$-THC (B), and CBD (C). The concentrations of the cannabinoids were $0 \mu \mathrm{M}$ (control), $\bullet 50 \mu \mathrm{M}, \boldsymbol{\Lambda} ;$; and $100 \mu \mathrm{M}$, $\boldsymbol{\square}$. Each point is the mean of duplicate incubations of two independent experiments. The double reciprocal plot (A) partially magnified is shown on the right side of (A). 
and CBN. The inhibition constants $\left(\mathrm{K}_{\mathrm{i}}, \mu \mathrm{M}\right)$ for $\Delta^{9}-$ THC, CBD, and CBN were $15.9,124.4$, and 4.5 , respectively.

\section{DISCUSSION}

Several studies have shown that cannabinoids have inhibitory effects on a variety of enzyme activities. In particular, CBD is known to inhibit hepatic drug-metabolizing enzymes through its interaction with cytochrome P450. ${ }^{18-20)}$ Narimatsu et al..$^{21)}$ demonstrated that CBD, but not $\Delta^{9}-\mathrm{THC}$ and CBN, competitively inhibited testosterone $2 \alpha$ - and $16 \alpha$-hydroxylation in male rat liver microsomes and that the inhibitory effects were supported by an in vivo investigation. On the other hand, it was reported that not only CBD but also both $\Delta^{9}$-THC and CBN showed inhibitory effects on rat hepatic microsomal enzyme activities, $N$-demethylation of aminopyrine and morphine, ${ }^{22)}$ and microsomal anandamide amidohydrolase activity in mouse brain. ${ }^{23)}$ It was also reported that the hydroxylation of the same sites on the structures of $\Delta^{9}$-THC and testosterone were catalyzed by rat male-specific cytochrome $\mathrm{P} 450$ (CYP2C11), suggesting that the oxidation of testosterone might be inhibited competitively by the cannabinoid. ${ }^{24)}$ It is well known that the structure of $\Delta^{9}$-THC is similar to those of steroids such as testosterone and estradiol. ${ }^{25)}$ However, there is no direct evidence of the binding of $\Delta^{9}$-THC to the receptors of steroids such as estrogen and androgen. ${ }^{11)}$ Recently, we have shown that testosterone $6 \beta$ - and $16 \alpha$-hydroxylase activities in rat liver microsomes were inhibited by $\Delta^{9}$-THC, CBD, and CBN as well as by crude extracts of marijuana, and that the cannabinoids inhibited progesterone $17 \alpha$-hydroxylase activity in rat testis microsomes. ${ }^{11)}$ However, the inhibition of $17 \alpha$-hydroxylase activity was detected at relatively higher concentrations compared with the inhibition of testosterone $6 \beta$ - and $16 \alpha$-hydroxylation in rat liver microsomes, and effects of the cannabinoids on kinetic parameters of rat testis $17 \alpha$ hydroxylase activity were not examined. In the present study, we studied the inhibitory effects of cannabinoids on progesterone $17 \alpha$-hydroxylase activity and found that the activity was significantly inhibited by cannabinoids at concentrations greater than $100 \mu \mathrm{M}$. On the other hand, our previous study demonstrated that progesterone $17 \alpha$-hydroxylase activity was inhibited to 88,50 , and $27 \%$, respectively, by relatively higher concentrations of CBD,
$\Delta^{9}$-THC, and CBN $1000 \mu \mathrm{M}$, while the activity was not significantly affected by concentrations of less than $100 \mu \mathrm{M}$ of these cannabinoids. ${ }^{11)}$ There might be some reason for the difference between these results. One reason is the influence of substrate concentration added to the reaction mixture. The substrate concentration $(75 \mathrm{nM})$ used in the present study was lower than that $(40 \mu \mathrm{M})$ in the previous study. ${ }^{11}$ The other reason may be that the method used to determine progesterone $17 \alpha$-hydroxylase activity in the present study was different from that reported previously. In this study, the activity of $17 \alpha$-hydroxylase was calculated as the sum of $\left[{ }^{3} \mathrm{H}\right] 17 \alpha$-hydroxyprogesterone and $\left[{ }^{3} \mathrm{H}\right]$ androstenedione formed from $\left[{ }^{3} \mathrm{H}\right]$ progesterone, although the previous report investigated the inhibitory effects of cannabinoids on $17 \alpha$-hydroxylase activity by determining only the amount of $17 \alpha$-hydroxyprogesterone formed. These results suggest that these cannabinoids may have more potent inhibitory effects on 17,20-lyase than those on $17 \alpha$-hydroxylase. The data therefore do not conflict with the inhibitory effects of the cannabinoids on progesterone $17 \alpha$-hydroxylase activity.

Kinetic analyses showed that the inhibition by $\mathrm{CBN}$ was the competitive type and different from the mixed-type inhibition by $\Delta^{9}$-THC and CBD. As a result, the inhibitory effects of the cannabinoids on rat testis $17 \alpha$-hydroxylase activity were unrelated to their psychoactivity, because $\mathrm{CBN}$, which has extremely low psychoactivity, exhibited the highest potency in the inhibition of $17 \alpha$-hydroxylase activity among the cannabinoids examined. The similarity of chemical structures between the cannabinoids and progesterone was implicated in the possibility that the cannabinoids are used as substrates for rat testis $17 \alpha$-hydroxylase. Although the hydroxylation of cannabinoids catalyzed by rat testis $17 \alpha$-hydroxylase is not known, their metabolic interactions may be responsible for the inhibition by the cannabinoids of progesterone $17 \alpha$-hydroxylase activity.

In humans, dose-related oligospermia has been observed in chronic marijuana users. ${ }^{26)}$ Similarly, a $58 \%$ decrease in sperm concentration was reported in chronic users after intensive marijuana smoking without a significant change in luteinizing hormone (LH) or testosterone levels. ${ }^{27)}$ Reversible reductions in sperm production were seen 5 to 6 weeks after the initiation of intensive smoking, suggesting an effect on sperm production. ${ }^{28)}$ In addition, abnormal sperm morphology and lower testosterone levels have been reported in chronic marijuana smokers. ${ }^{26,29)}$ However, in contrast to those findings, it has 
been reported that testosterone levels showed no significant changes after a 21-day period of intense marijuana smoking. ${ }^{30)}$ Thus the results of human studies on the effects of cannabinoids on testosterone production have been conflicting.

Rat $17 \alpha$-hydroxylase/17,20-lyase was cloned from testis and the deduced amino acid sequence was reported to have $69 \%$ identity with that of the human form. ${ }^{31)}$ The activity profile of rat testis $17 \alpha$ hydroxylase/17,20-lyase expressed in Cos 1 cells is distinct from that of the human enzyme, which is unable to catalyze 17,20-lyase at significant rates. Alternatively, this ability of rat testis $17 \alpha$-hydroxylase/17,20-lyase to convert $17 \alpha$-hydroxyprogesterone to androstenedione is not shared with the human enzyme form. Further study is therefore necessary to clarify whether cannabinoids inhibit $17 \alpha$-hydroxylase activity in marijuana smokers.

Acknowledgements This work was supported by a Grant-in-Aid for Scientific Research from the Ministry of Education, Science, Sports, Culture and Technology of Japan.

\section{REFERENCES}

1) Dalterio, S. and Bartke, A. (1979) Perinatal exposure to cannabinoids alters male reproductive function in mice. Science, 205, 1420-1422.

2) Dalterio, S., Bartke, A. and Mayfield, D. (1981) $\Delta^{9}-$ Tetrahydrocannabinol increases plasma testosterone concentrations in mice. Science, 213, 581-582.

3) Harclerode, J. (1984) Endocrine effects of Marijuana in the male: preclinical studies. NIDA Res. Monogr., 44, 46-64.

4) Brown, T. T. and Dobs, A. S. (2002) Endocrine effects of marijuana. J. Clin. Pharmacol., 42, 90S96S.

5) Burstein, S., Hunter, S. A., Shoupe, T. S. and Taylor, P. (1978) Cannabinoid inhibition of testosterone synthesis by mouse Leydig cells. Res. Commun. Chem. Pathol. Pharmacol., 19, 557-560.

6) Burstein, S., Hunter, S. A. and Shoupe, T. S. (1979) Site of inhibition of Leydig cell testosterone synthesis by $\Delta^{1}$-tetrahydrocannabinol. Mol. Pharmacol., 15, 633-640.

7) Burstein, S., Hunter, S. A. and Shoupe, T. S. (1978) Inhibition of cholesterol esterases by $\Delta^{1}$-tetrahydrocannabinol. Life Sci., 23, 979-982.

8) Dalterio, S., Bartke, A. and Burstein, S. (1976) Cannabinoids inhibit testosterone secretion by mouse testes in vitro. Science, 196, 1472-1473.

9) Jakubovic, A., McGeer, E. G. and McGeer, P. L. (1978) Biochemical alterations induced by cannabinoids in the Leydig cells of the rat testis in vitro : effects on testosterone and protein synthesis. In Marihuana: Biological Effects (Nahas, G. G. and Paton, W. D., Eds.), Pergamon Press, New York, pp. 251-264.

10) List, A., Nazar, B., Nyquist, S. and Harclerode, J. (1977) The effects of $\Delta^{9}$-tetrahydrocannabinol and cannabidiol on the metabolism of gonadal steroids in the rat. Drug Metab. Dispos., 5, 268-272.

11) Watanabe, K., Motoya, E., Matsuzawa, N., Funahashi, T., Kimura, T., Matsunaga, T., Arizono, K. and Yamamoto, I. (2005) Marijuana extracts possess the effects like the endocrine disrupting chemicals. Toxicology, 206, 471-478.

12) Nakajin, S., Shively, J. E., Yuan, P. M. and Hall, P. F. (1981) Microsomal cytochrome P450 from neonatal pig testis: Two enzymatic activities ( $17 \alpha$-hydroxylase and C17,20-lyase) associated with one protein. Biochemistry, 20, 4037-4042.

13) Dalla Valle, L., Ramina, A., Vianello, S., Belvedere, P. and Colombo, L. (1996) Kinetic analysis of duodenal and testicular cytochrome $P 450 \mathrm{c} 17$ in the rat. $J$. Steroid Biochem. Mol. Biol., 58, 577-584.

14) Johnson, D. C. (1979) Steroid $17 \alpha$-hydroxylase of the rat adrenal. J. Steroid Biochem., 10, 397-400.

15) Dalterio, S., Bartke, A., Roberson, C., Watson, D. and Burstein, S. (1978) Direct and pituitary-mediated effects of $\Delta^{9}$-THC and cannabinol on the testis. Pharmacol. Biochem. Behav., 8, 673-678.

16) Aramaki, H., Tomiyasu, N., Yoshimura, H. and Tsukamoto, H. (1968) Forensic chemical study on marihuana. I. A detection method of the principal constituents by thin-layer and gas chromatographies. Chem. Pharm. Bull., 16, 822-826.

17) Lowry, O. H., Rosebrough, N. J., Farr, A. L. and Randall, R. J. (1951) Protein measurement with the Folin phenol reagent. J. Biol. Chem., 193, 265-271.

18) Watanabe, K., Hamajima, K., Narimatsu, S., Yamamoto, I. and Yoshimura, H. (1986) Effects of two cannabinoids on hepatic microsomal cytochrome P-450. J. Pharmacobio-Dyn., 9, 39-45.

19) Watanabe, K., Arai, M., Narimatsu, S., Yamamoto, I. and Yoshimura, H. (1987) Self-catalyzed inactivation of cytochrome P-450 during microsomal metabolism of cannabidiol. Biochem. Pharmacol., 36, 3371-3377.

20) Bornheim, L. M., Everhart, E. T., Li, J. and Correia, M. A. (1993) Characterization of cannabidiol-mediated cytochrome P450 inactivation. Biochem. Pharmacol., 45, 1323-1331.

21) Narimatsu, S., Watanabe, K., Yamamoto, I. and 
Yoshimura, H. (1988) Mechanism for inhibitory effect of cannabidiol on microsomal testosterone oxidation in male rat liver. Drug Metab. Dispos., 16, 880-889.

22) Fernandes, M., Warning, N., Christ, W. and Hill, R. (1973) Interactions of several cannabinoids with the hepatic drug metabolizing system. Biochem. Pharmacol., 22, 2981-2987.

23) Watanabe, K., Kayano, Y., Matsunaga, T., Yamamoto, I. and Yoshimura, H. (1996) Inhibition of anandamide amidase activity in mouse brain microsomes by cannabinoids. Biol. Pharm. Bull., 19, 1109-1111.

24) Narimatsu, S., Watanabe, K., Matsunaga, T., Yamamoto, I., Imaoka, S., Funae, Y. and Yoshimura, H. (1990) Cytochrome P-450 isozymes in metabolic activation of $\Delta^{9}$-tetrahydrocannabinol by rat liver microsomes. Drug Metab. Dispos., 18, 943-948.

25) Martin, B. R. (1986) Cellular effects of cannabinoids. Pharmacol. Rev., 38, 45-74.

26) Kolodny, R. C., Masters, W. H., Kolodner, R. M. and Toro, G. (1974) Depression of plasma testosterone after chronic intensive marihuana use. N. Engl. J. Med., 290, 872-874.

27) Hembree, W. C., Zeidenberg, P. and Nahas, G. G.
(1976) Marihuana's effect on human gonadal function. In Marihuana: Chemistry, Biochemistry, and Cellular Effects (Nahas, G. G., Ed.), SpringerVerlag, New York, pp. 521-532.

28) Hembree, W. C., Zeidenberg, P. and Nahas, G. G. (1979) Changes in human spermatozoa associated with high dose marijuana smoking. In Marihuana: Biological Effects (Nahas, G. G. and Paton, W., Eds.), Pergamon Press, New York, pp. 429-439.

29) Issidorides, M. R. (1979) Observations in chronic hashish users: nuclear aberrations in blood and sperm and abnormal acrosomes in spermatozoa. In Marihuana: Biological Effects (Nahas, G. G. and Paton, W., Eds.), Pergamon Press, New York, pp. 377-388.

30) Mendelson, J., Kuehnle, J., Ellingboe, J. and Barbor, T. (1974) Plasma testosterone levels before during and after chronic marijuana smoking. N. Engl. J. Med., 291, 1051-1055.

31) Fevold, H. R., Lorence, M. C., McCarthy, J. L., Trant, J. M., Kagimoto, M., Waterman, M. R. and Mason, J. I. (1989) Rat P450 ${ }_{17 \alpha}$ from testis: characterization of a full-length cDNA encoding a unique steroid hydroxylase capable of catalyzing both $\Delta^{4}$ and $\Delta^{5}$-steroid-17,20-lyase reactions. Mol. Endocrinol., 3, 968-975. 